\title{
Isolated Esophageal Crohn's Disease with Diffuse Stricture
}

\author{
Mohamed Alhaj Moustafa \\ Department of General and Thoracic Surgery, IDA Hospital, Aleppo, Syria \\ Email:m_haj_m@hotmail.com,m.haj.m@my.com
}

How to cite this paper: Alhaj Moustafa, M. (2021) Isolated Esophageal Crohn's Disease with Diffuse Stricture. Open Journal of Thoracic Surgery, 11, 96-106. https://doi.org/10.4236/ojts.2021.114013

Received: October 26, 2021

Accepted: December 25, 2021

Published: December 28, 2021

Copyright $\odot 2021$ by author(s) and Scientific Research Publishing Inc. This work is licensed under the Creative Commons Attribution International License (CC BY 4.0).

http://creativecommons.org/licenses/by/4.0/

\begin{abstract}
Background: Esophageal strictures are considered to be one of the most challenging matters for gastroenterologist, general and thoracic surgeons in diagnosis and management. They can be grouped into three general categories: intrinsic diseases, extrinsic diseases, and diseases that disrupt esophageal peristalsis and/or lower esophageal sphincter (LES) function. Crohn's disease $(\mathrm{CD})$ is a very rare cause of esophageal stricture. The prevalence of esophageal $\mathrm{CD}$ ranges from $1 \%$ to $2 \%$ in adults with $\mathrm{CD}$. It is almost diagnosed lately when complications have occurred as Strictures, fissures, esophagobronchial fistulas, and mediastinal abscesses. Case Report: Thirty-nine years old Kurdish patient, referred to our department for evaluation. Although many consultations during the last two years, the Pt was still undiagnosed. She had progressive dysphagia, and weight loss of about $25 \mathrm{~kg}$. She had no other digestive or extra digestive complaint, nor caustic ingestion history and nor drug history. Chest CT scan and UGI Contrast study revealed diffuse smooth and regular esophageal stenosis. Attempts to do upper endoscopy and biopsy failed due to severe stenosis. Prolonged medical history and radiologic signs exclude malignancy, so esophagectomy with stomach pull-through was done by the aid of VATS and laparoscopy with excellent results. Pathological finding of the resected esophagus suggested the diagnosis of Crohn's disease CD. Conclusions: $\mathrm{CD}$ is a rare cause of esophageal stricture and still to be a challenging early diagnosis due to the low specificity of clinical manifestations (aphthous ulcers), histologic findings (absence of granulomas), and endoscopic findings. So many patients have been diagnosed with complications (esophageal strictures, fistulas) which needed surgical treatment, adding greater morbidity and mortality. MIS (thoracoscopy-laparoscopy) is valuable in decreasing the morbidity and mortality and improving the quality of life for those patients.
\end{abstract}

\section{Keywords}

Isolated Esophageal Crohn's Disease, Crohn's Disease, Esophageal Stricture 


\section{Introduction}

Esophageal strictures are considered some of the most challenging matters for gastroenterologist, general and thoracic surgeons. They can be grouped into three general categories: 1) intrinsic diseases that narrow the esophageal lumen through inflammation, fibrosis, or neoplasia; 2) extrinsic diseases that compromise the esophageal lumen by direct invasion or lymph node enlargement; and 3) diseases that disrupt esophageal peristalsis and/or lower esophageal sphincter (LES) function by their effects on esophageal smooth muscle and its innervation [1].

Many diseases can cause esophageal stricture. These include gastro-esophageal reflux disease, autoimmune, infectious (herpes simplex virus, cytomegalovirus, mycobacteria, syphilis, histoplasmosis), caustic agent ingestion, sarcoidosis, Behcet's disease, congenital, iatrogenic, medication-induced, radiation-induced, malignant, and idiopathic diseases [2].

The etiology of esophageal stricture can usually be identified using radiologic and endoscopic modalities and can be confirmed by tissue biopsy. Using manometry can be diagnostic when dysmotility is suspected as the primary process. Computed tomography (CT) scanning and endoscopic ultrasonography are valuable aids in staging malignant stricture. Fortunately, most benign esophageal strictures are amenable to pharmacologic, endoscopic, and/or surgical interventions [1].

Here, we present a case of a very rare cause of esophageal stricture. It's Crohn's disease, especially the lesion was isolated without intestinal or colonic involvement.

\section{Case Report}

Thirty nine years old Kurdish patient, lives in a remote village, admitted in the internal medicine department in our hospital to investigate a weight loss, during a chest CT scan they discovered a long stenosis of esophagus (Figure 1). She referred to our thoracic \& general surgery department for evaluation.

Although many consultations during the last two years, Pt still undiagnosed, she had progressive dysphagia, which got worse in the last six months, until she
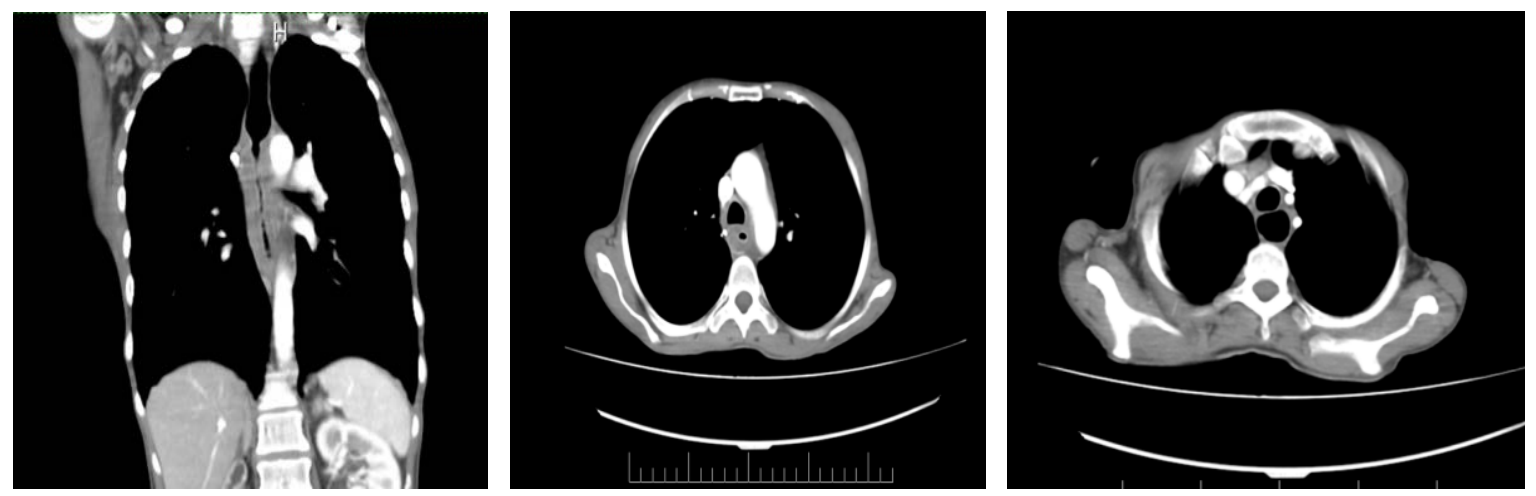

Figure 1. Chest Ct scan revealed long esophageal stenosis with muscular layer thickness. 
couldn't swallow any solid food, just fluids. She lost about $25 \mathrm{~kg}$ of her weight.

She had no other digestive or extra digestive complaint, nor caustic ingestion history, nor drug history.

She appeared weak but viable, other examinations were within normal limits.

UGI Contrast study revealed diffuse smooth and regular esophageal stenosis for about $12 \mathrm{~cm}$ (Figure 2).

Attempts to do upper endoscopy and biopsies failed due to severe stenosis.

Prolonged medical history and radiologic signs, excluded malignancy, so the plan was esophagectomy with stomach pull-through through three phases.

First phase started thoracoscopically, $\mathrm{Pt}$ in left lateral decubitus position, right hemithorax introduced through three ports, the chest and the esophagus were explored, malignancy excluded, esophagus exposed, distally isolated, it was too thick for a long distance (approximately $12 \mathrm{~cm}$ ) from aortic arch level downward with severe adhesive to carina and left main bronchus, so the operation converted to open thoracotomy trans fifth intercostal space.

Isolation of esophagus continued up and down the lesion after ligation and cutting the azygos vein, then severe adhesion to carina and left main bronchus dissected by ligaSure. Finally, the esophagus was isolated totally from the apex of thorax to the diaphragmatic hiatus, air leak test from bronchus under water was negative, the chest drained, and the lung inflated, chest wall closed.

The second phase of the operation was done laparoscopically, the omentum was dissected from greater curvature preserving right gastroepiploic artery by ligaSure, after that the fundus was dissected from short gastric vessels until the left crura.

The lesser curvature was dissected distal to the right gastric artery, the left gastric artery was isolated and ligated, the dissection continued until the right crura. After that the abdominal esophagus is dissected from the diaphragmatic
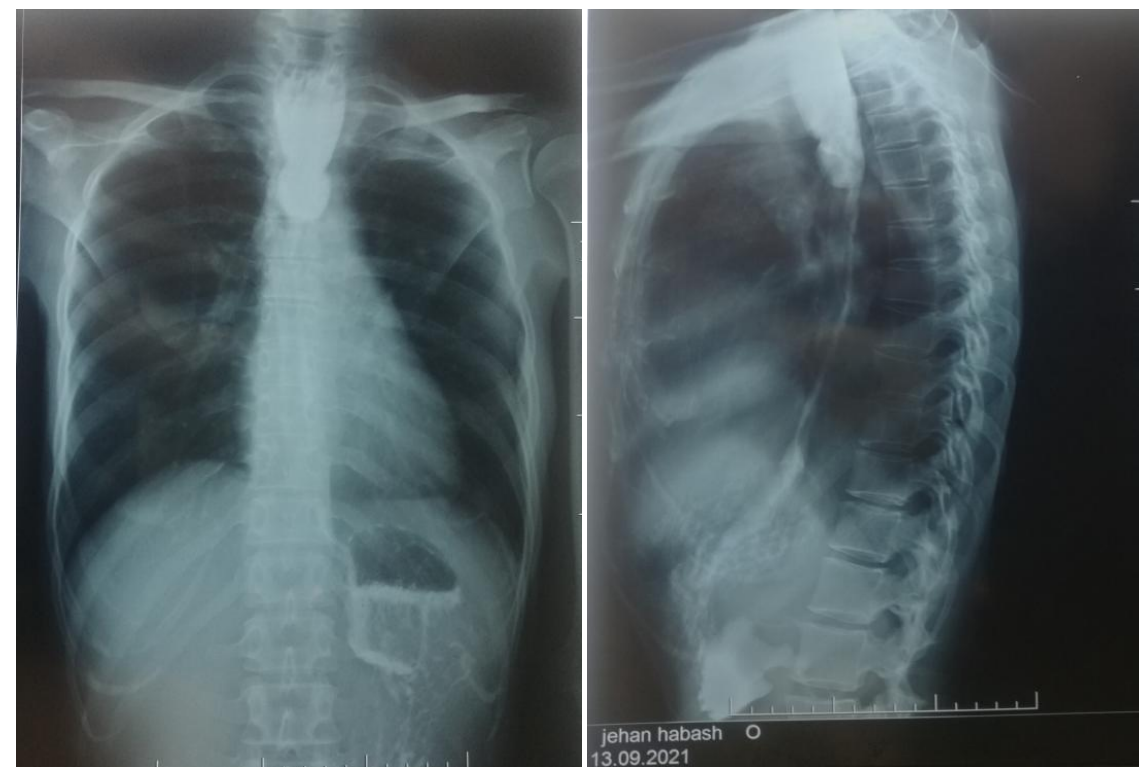

Figure 2. UGI Contrast study revealed long smooth regular esophageal stenosis. 
hiatus and became totally free, the abdomen was drained (Figure 3).

The third phase, cervically, was done through an incision medial to the left sternocleidomastoid muscle, the fascia dissected deeply, and the carotid sheath laterally retracted after ligation and cutting of middle thyroid vein, the cervical esophagus isolated, the stomach is pulled up through the cervical incision (Figure 4), the esophagus is resected (Figure 5), then the fundus of stomach is secured to prevertebral fascia by two sutures. After that one-layer interrupted esophago-gastric anastomosis was done by $2 / 0$ vicryl over the NG tube, cervical incision was drained and closed.

Patient recovered well without any complications.

On the fifth day the methylene blue test was done, no leakage, and the patient started drinking fluids. On the seventh day the chest tube and abdominal drain were removed, and the patient was discharged. Pt. is still under follow up.

Pathological findings of the resected esophagus suggest the diagnosis of Crohn's disease CD (Figure 6). The diagnosis depends on:

- Ulceration of the mucosa, fissuring deep (ulceration into the muscularis propria) may form fistulas (Figure 7, Figure 8).
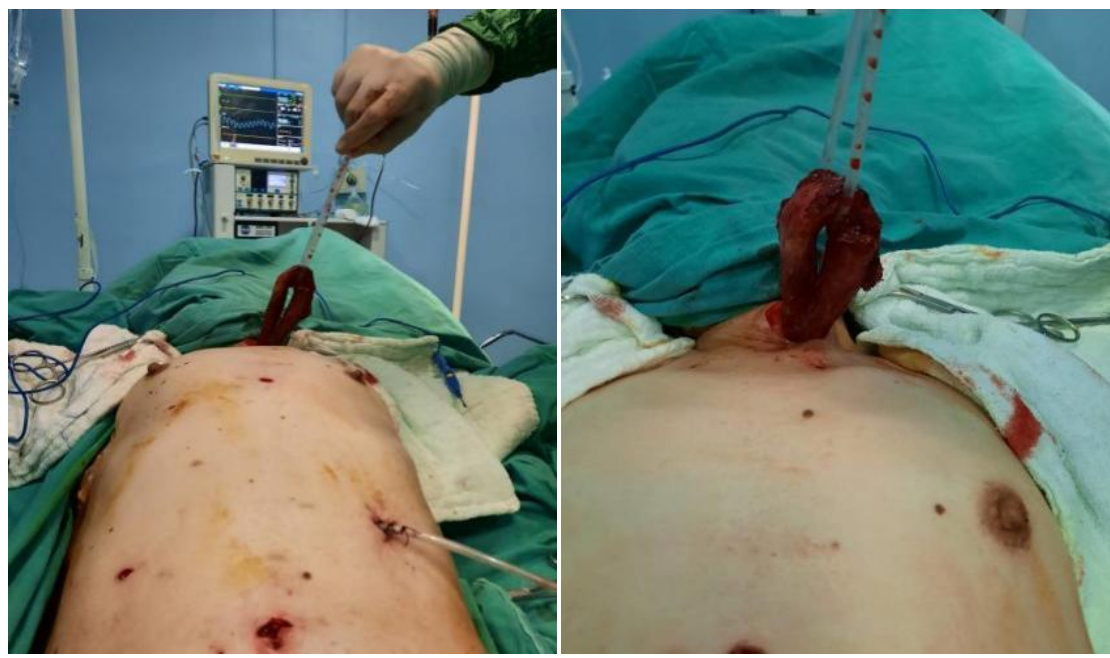

Figure 3. Abdominal phase, completed laparoscopically.
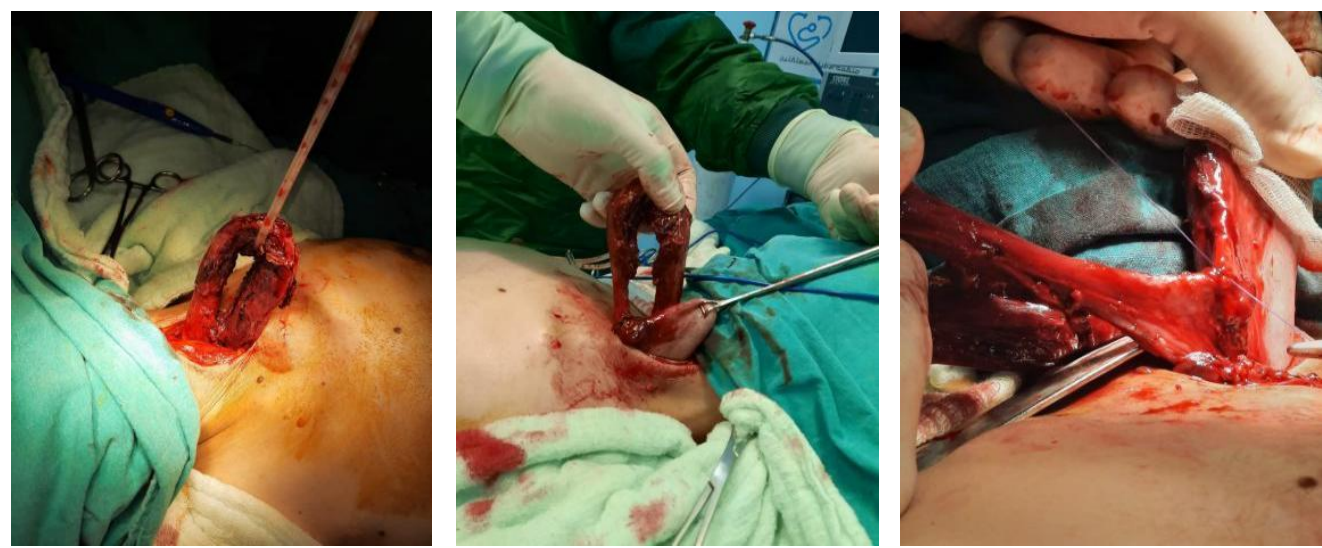

Figure 4. Cervical phase. 

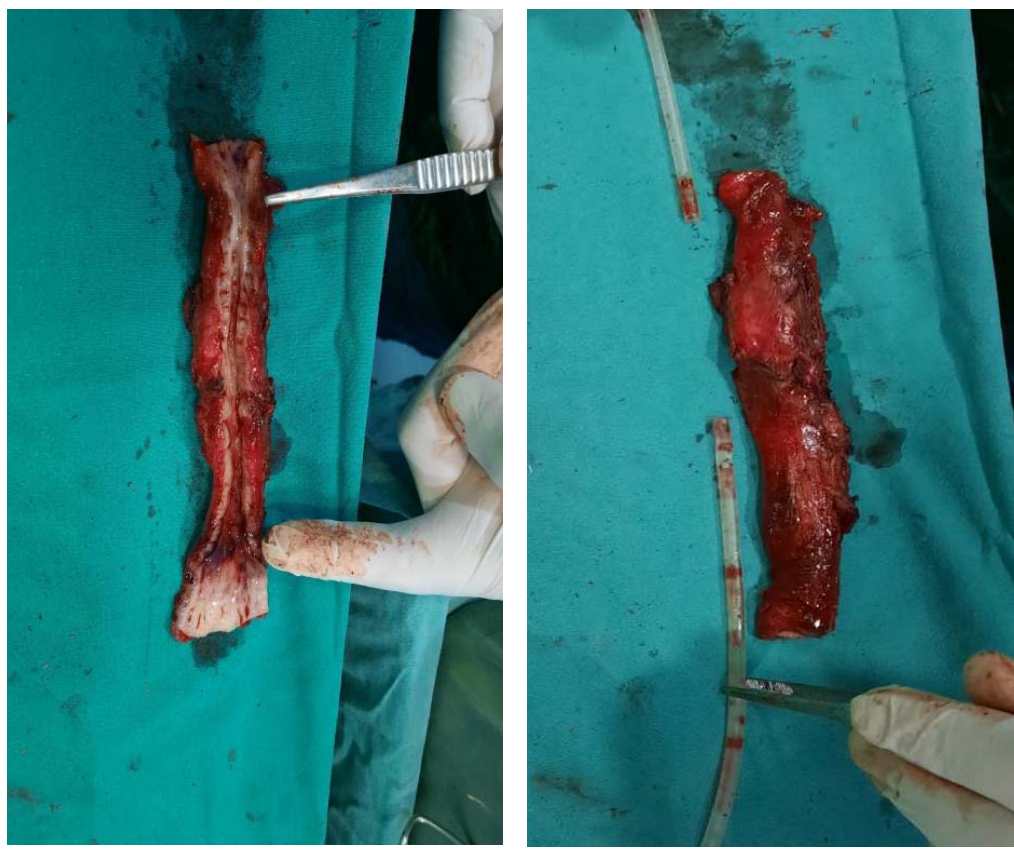

Figure 5. Resected esophagus, thickened muscular layer and ulcerated mucosa.

\begin{tabular}{|c|c|c|c|}
\hline $\begin{array}{l}\text { Sex } \\
\text { site } \\
\text { date }\end{array}$ & $\begin{array}{l}\text { F } \\
\text { Esophagus } \\
19 / 9 / 2021\end{array}$ & $\begin{array}{l}\text { Age } \\
\text { procedure } \\
\text { Doctor }\end{array}$ & $\begin{array}{l}39 \text { Y } \\
\text { Esophagectomy } \\
\text { Mohammad Haj Mostafa }\end{array}$ \\
\hline \multicolumn{4}{|c|}{ Gross: } \\
\hline \multicolumn{4}{|c|}{$\begin{array}{l}\text { A piece from esophagus measures } 12 \mathrm{~cm} \text { in length, cut sections show ulcerative area } \\
\text { measures } 8 \mathrm{~cm} \text {, } \\
11 \text { lymph nodes were isolated the largest } 1 \mathrm{~cm}\end{array}$} \\
\hline
\end{tabular}

\begin{tabular}{|l|}
\hline Microscopic: \\
\hline Sections show ulceration, fissuring of the mucosa with transmural inflammatory \\
infiltrate composed of lymphocytes follicles, plasma cells, and neutrophils, the \\
inflammatory infiltrate reach to the surrounding adipose tissue, prominent nerve \\
plexuses \\
Sections show reactive lymph nodes and inflammation within the adipose tissue \\
\hline
\end{tabular}

\begin{tabular}{|l|}
\hline Diagnosis: \\
\hline Crohn's disease of the Esophagus \\
- 11 reactive lymph nodes \\
- No malignancy \\
\hline
\end{tabular}

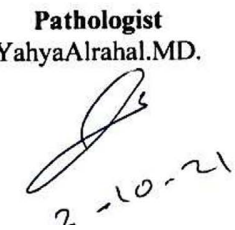

Figure 6. Pathology report.

- Inflammatory infiltration with lymphocytes, plasma cells and neutrophils (Figure 9, Figure 10).

- Severe hyperplasia of muscularis mucosa, transmural inflammation, and lymphocytes forming follicles (Figure 11). 


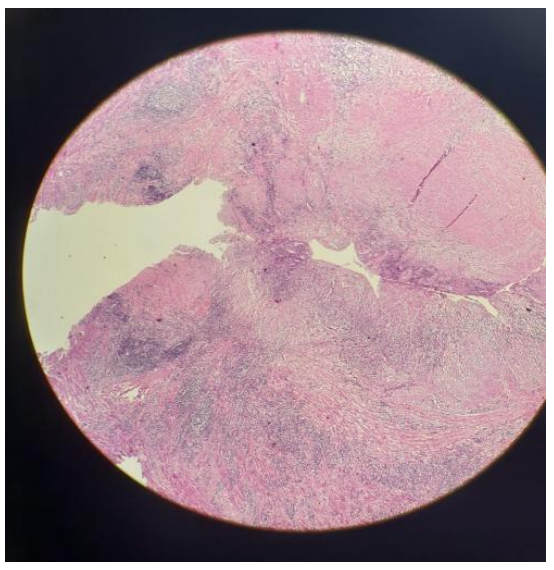

Figure 7. Ulceration of the mucosa fissuring (deep ulceration into the muscularis propria) may form fistulas.

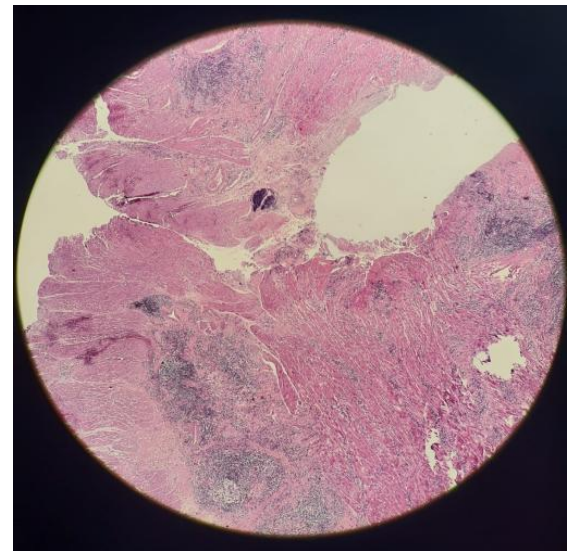

Figure 8. As above with fistula.

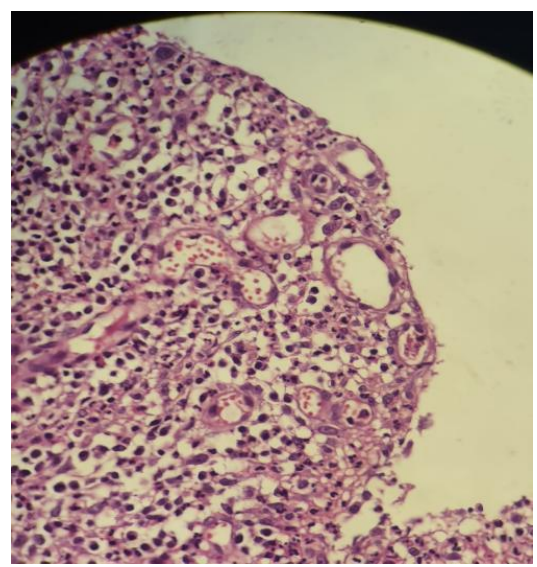

Figure 9. Ulceration of mucosa. inflammatory infiltrate.

- Transmural inflammation reaches the muscular layer (Figure 12).

- Transmural inflammation reaches the surrounding tissue (Figure 13).

- Nerve plexuses hyperplasia (Figure 14).

- Reactive follicular hyperplasia in the lymph nodes (Figure 15(a), Figure 15(b)). 


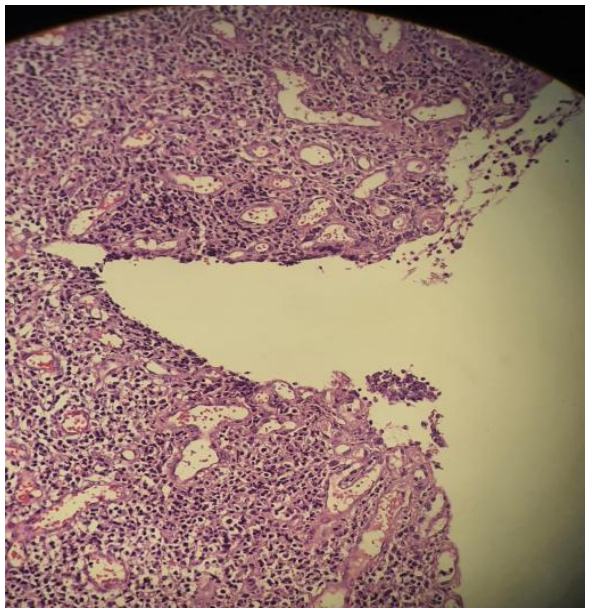

Figure 10. Lymphocytes, plasma cells and neutrophils.

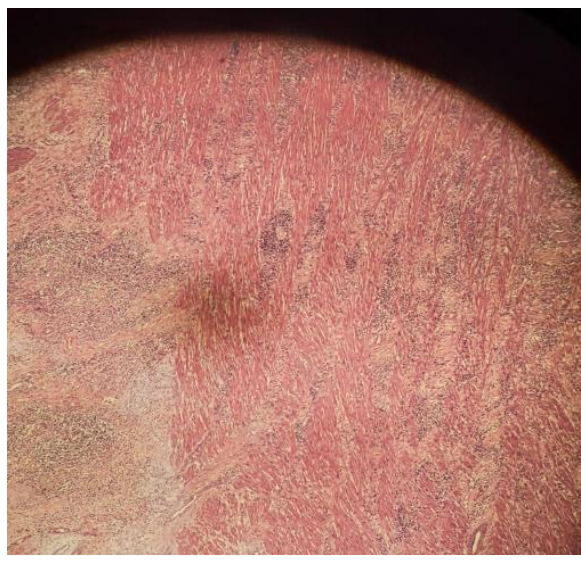

Figure 11. Severe hyperplasia of muscularis mucosa.

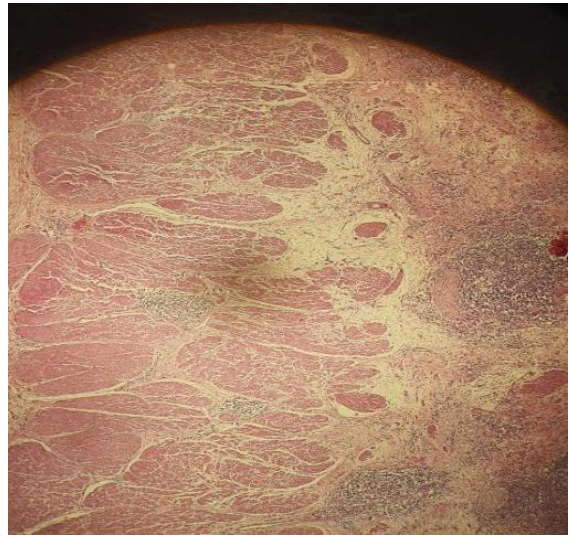

Figure 12. Transmural inflammation reaches the muscular layer.

\section{Discussion}

Crohn's disease (CD) is a chronic inflammatory disease of the gastrointestinal (GI) tract, characterized by segmental, granulomatous, and trans-mural inflammation with episodic relapse and remission, leading to complications of strictures, fistulas, or abscesses. Although CD can occur anywhere from the oral 


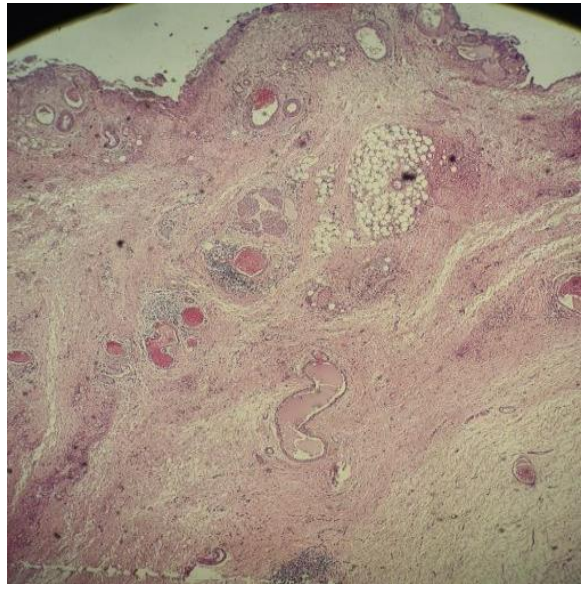

Figure 13. Transmural inflammation reaches the surrounding tissue.

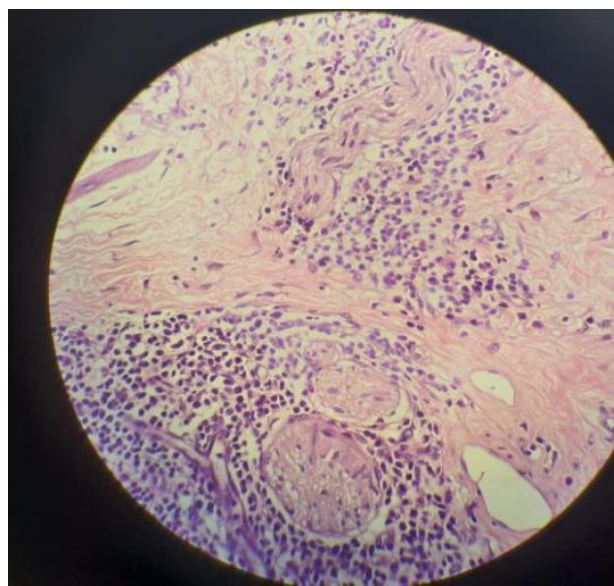

Figure 14. Nerve plexuses hyperplasia.

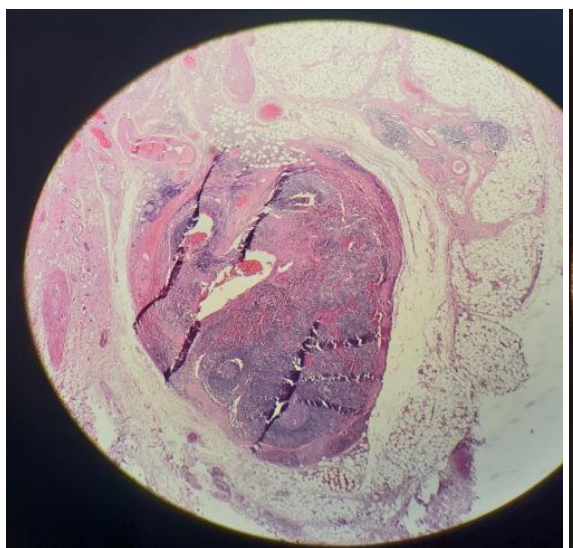

(a)

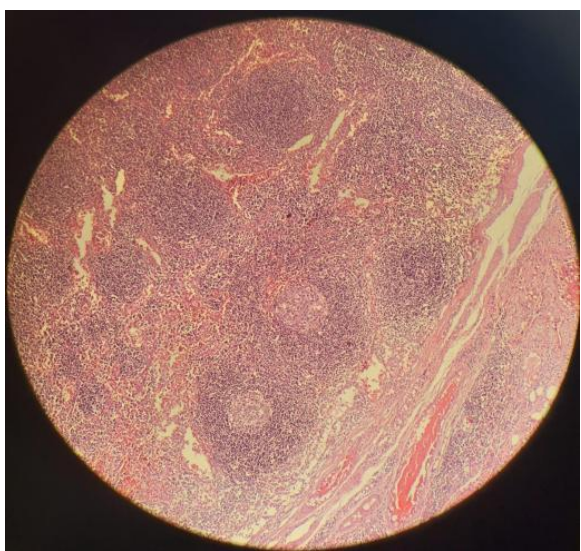

(b)

Figure 15. Reactive follicular hyperplasia in the lymph nodes.

cavity to the anus, the most usual occurrences are in the terminal ileum and colon. The esophagus is the least common location for $\mathrm{CD}$, the most common site of occurrence is mid or distal esophagus [2]. Since Franklin and Taylor in 1950 reported the first case of esophageal $\mathrm{CD}$, less than 100 cases have been reported. 
Isolated esophageal involvement by $\mathrm{CD}$ has been previously reported in only 10 cases [3].

The prevalence of esophageal disease in adults with $\mathrm{CD}$ has been estimated to be $1.8 \%$. Most patients have distal CD involvement that is diagnosed initially and presents later with symptoms suggestive of esophageal disease, but some patients, albeit few, present with isolated esophageal disease [3].

In the recent quarter century, prevalence of esophageal $\mathrm{CD}$ has gradually increased ranging from $0.2 \%$ in a couple of retrospective observational series to $11 \%$ in another. Although 14 years apart, Decker et al. and De Felice et al. both found no more than a $0.2 \%$ prevalence of $\mathrm{CD}$ with esophageal involvement in a patient population of 9900 and 12,367 respectively, while D'Haens et al., demonstrated an $11 \%$ prevalence in 124 patients. All of the series had concurrent CD elsewhere on the GI tract, except De Felicia and colleagues designated 3 of 24 cases as having remote esophageal CD [2].

In a review of the literature performed by Ohta et al., in only 10 of 77 (13\%) cases was the esophagus the only organ affected. None of these cases were able to be diagnosed as CD preoperatively. Ileocolic lesions developed after esophageal lesions in only 5 patients (6.5\%). In the remaining 62 patients (80.5\%), ileocolic synchronous lesions had existed with the esophageal lesions [3].

Therefore, isolated esophageal $\mathrm{CD}$ is an even more rare finding that has been described in the aforementioned studies among scarce case reports [2].

Esophageal disease has a higher predisposition to stricturing complications, greater aggressiveness with the formation of fistulas to the trachea, bronchial tubes, lungs, and stomach. Clinical onset in younger patients with a mean age of 35 years, a lower body mass index, and higher platelet count, is indicative of a systemic inflammatory response. They are a poor outcome marker and therefore early treatment should be started, stepping up the therapy if there is no symptomatic or endoscopic improvement [4].

The majority of patients present for evaluation of progressive dysphagia, odynophagia, worsening reflux [5] [6] (epigastric pain, heartburn, nonspecific chest pain), failure to thrive, weight loss and decreased appetite.

Endoscopy with biopsy is always mandatory to diagnose any type of CD. Esophageal CD marked by aphthous ulcerations, mucosal nodules or the typical CD's cobblestone appearance [6], an advanced disease showing esophageal fissures, fistulas and strictures [4].

Histology shows nonspecific findings. These usually contain evidence of chronic inflammation with plasma cells and lymphocytes, infrequently non-caseating granuloma formation and acute inflammation, showing predominantly polymorphonuclear neutrophils.

Complications include stricture and fistula formation (esophagobronchial fistula, esophagogastric fistula) which lead to (recurrent mediastinitis, abscesses, or pneumomediastinum) [2].

Treatment of esophageal $\mathrm{CD}$ is the same as other forms of the disease. 
Medical: It depend on glucocorticoids, acetylsalicylic acid derivatives (mesalazine and sulfasalazine), immunosuppressants (azathioprine), and biologic treatments (infliximab,anti-TNFa injection) [4].

Endoscopic therapy including stricture dilation with and without steroid injections, and infliximab injections for fistulas with low effectiveness [5].

Surgical operations reserved for complicated fistula or obstruction or those with null response to drugs [4]. Esophagectomy with gastric pull-through was the typical surgical procedure performed as described in several literature reviews [2] [5].

Davidson and Sawyers reviewed the literature and identified that 13 of 20 patients with esophageal $\mathrm{CD}$ were treated with surgery. All patients underwent esophagectomy. Four patients had esophageal fistula, and 5 patients underwent surgical resection because cancer could not be ruled out by preoperative studies. Postoperative mortality rate was $25 \%$ [7].

\section{Conclusions}

$\mathrm{CD}$ is a rare cause of esophageal stricture and still to be a challenging diagnosis due to the low specificity of clinical manifestations (aphthous ulcers), histologic findings (absence of granulomas), and endoscopic findings. So many patients are diagnosed with complications (esophageal strictures, fistulas) which need surgical treatment, adding greater morbidity and mortality [4] [8].

For early diagnosis of isolated esophageal $\mathrm{CD}$, upper endoscopy should be considered for anyone with upper GI symptoms refractory to acid suppression therapy, antibiotics, especially for those who are less than 50 years of age. In addition, those with previous diagnosis of CD presenting with upper GI symptoms should always prompt a new or repeat upper endoscopy examination [6].

Rare causes must be kept in mind when we encounter esophageal stricture. No efforts must be reserved to reach to the specific diagnosis, then to select the more suitable modality of management.

MIS (thoracoscopy-laparoscopy) is valuable in decreasing the morbidity and mortality and improving the quality of life for those patients.

\section{Consent}

A written informed consent was obtained from the patient for publication of this case report and any accompanying images. A copy of the written consent is available for review by the Editor-in-Chief of this journal.

\section{Conflicts of Interest}

The author declares no conflicts of interest regarding the publication of this paper.

\section{References}

[1] Kumbum, K., Talavera, F., Anand, B.S., Cerulli, M.A., Mukherjee, S. and Vasudeva, R. (2019) Esophageal Stricture: Background, Pathophysiology, Etiology. 
https://emedicine.medscape.com/article/175098-overview

[2] Mathur, A.K. and Lysa, H.O. (2018) Isolated Crohn's Disease of Esophagus: A Rarest of Rare Presentation. Gastroenterology \& Hepatology, 9, 168-170.

https://doi.org/10.15406/ghoa.2018.09.00318

[3] Remes-Troche, J.M., Argote-Greene, M., Rubio-Tapia, A., Martínez-Benítez, B., Reyes, E., Medina-Franco, H. and Valdovinos, M.A. (2005) Progressive Dysphagia Caused by Isolated Esophageal Involvement of Crohn's Disease. Inflammatory Bowel Diseases, 11, 515-517. https://doi.org/10.1002/ibd.3780110517

[4] Loreto-Brand, M., Fernández-Pérez, A., Celeiro-Muñoz, C., Álvarez-Castro, A. and Bustamante-Montalvo, M. (2015) Crohn's Disease: Upper Gastrointestinal Involvement. Revista de Gastroenterología de México, 80, 282-285.

https://doi.org/10.1016/j.rgmxen.2015.08.001

[5] De Felice, K.M., Katzka, D.A. and Raffles, L.E. (2015) Crohn's Disease of the Esophagus: Clinical Features and Treatment Outcomes in the Biologic Era. Inflammatory Bowel Diseases, 21, 2106-2113. https://doi.org/10.1097/MIB.0000000000000469

[6] Davis, K.G. (2015) Crohn's Disease of the Foregut. Surgical Clinics of North America, 95, 1183-1193. https://doi.org/10.1016/j.suc.2015.07.004

[7] Davidson, J.A.T. and Sawyers, J.L. (1983) Crohn's Disease of the Esophagus. The American Journal of Surgery, 49, 168-172.

[8] Wang, W., Ni, Y., Ke, C., et al. (2012) Isolated Crohn's Disease of the Esophagus with Esophageal-Mediastinal Fistula Formation. World Journal of Surgical Oncology, 10, 208. https://doi.org/10.1186/1477-7819-10-208
Abbreviations
CD Crohn's disease
MIS Minimal invasive surgery 